\title{
ERRATUM
}

\section{Contribution of the straightening effect of the parent artery to decreased recanalization in stent-assisted coiling of large aneurysms}

TO THE READERSHIP: Errors appeared in our paper (Ishii A, Chihara H, Kikuchi T, et al: Contribution of the straightening effect of the parent artery to decreased recanalization in stent-assisted coiling of large aneurysms. J Neurosurg 127:1063-1069, 2017).

First, we wish to correct the description regarding the statistical analysis used in our study. In the Statistical Analysis subsection, we originally stated, "The rates of recanalization were analyzed using the Mann-Whitney Utest." That was an error. We have corrected the statement to read, "The rates of recanalization were analyzed using Fisher's exact test or the likelihood ratio test." In Table 2, the $\mathrm{p}$ value of 0.04 given for the difference in recanalization rates between groups $\mathrm{S}$ and NS was calculated using Fisher's exact test. In Table 5, the $\mathrm{p}$ value of 0.0401 given for the difference in recanalization rates between groups $0-20^{\circ}$ and $\geq 20^{\circ}$ was calculated using the likelihood ratio test. We have added statements to the table legends to make the distinction between statistical tests clear.
Second, we found an omission in the conflicts of interest that were disclosed in the present study. I received some speaker fees from Johnson \& Johnson and Stryker. The total amount of these fees is less than the amount that The Japan Neurosurgical Society mandates neurosurgeons to report. The speaker fees have been added to the Disclosures section of the article. The study was not sponsored by any company.

The article has been corrected online as of November 9, 2018.

Akira Ishii, MD, PhD

Kyoto University, Kyoto, Japan

INCLUDE WHEN CITING

Published online November 9, 2018; DOI: 10.3171/2018.10.JNS16501a.

CAANS 2019, except where prohibited by US copyright law 